\title{
Evaluating the efficiency of municipalities in collecting and processing municipal solid waste: A shared input DEA-model
}

\author{
Nicky Rogge \\ Simon De Jaeger
}
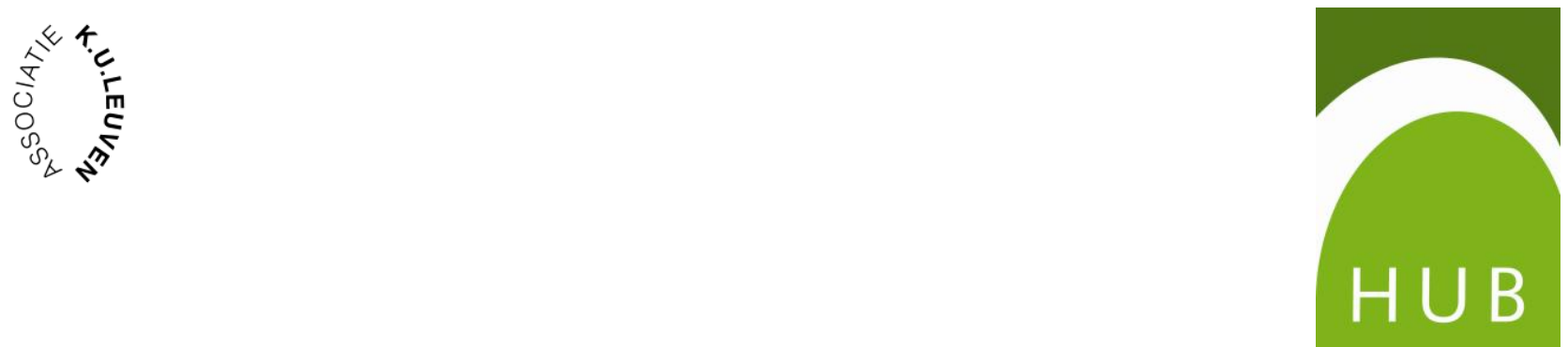


\title{
Evaluating the efficiency of municipalities in collecting and processing municipal solid waste: A shared input DEA-model
}

\author{
Nicky Rogge* ${ }^{*}$ and Simon De Jaeger ${ }^{\delta:}$ \\ (*): Hogeschool-Universiteit Brussel (HUBrussel) \\ Center for Business Management Research (CBMR) \\ Warmoesberg 26, 1000 Brussels (Belgium) \\ (\$): Katholieke Universiteit Leuven (KULeuven) \\ Faculty of Business and Economics \\ Naamsestraat 69, 3000 Leuven (Belgium); \\ and

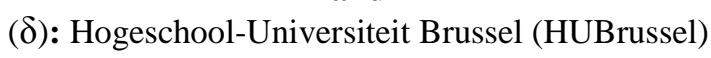 \\ Center for Economics and Corporate Sustainability (CEDON) \\ Warmoesberg 26, 1000 Brussels (Belgium)
}

\begin{abstract}
This paper proposed an adjusted "shared-input" version of the popular efficiency measurement technique Data Envelopment Analysis (DEA) that enables evaluating municipality waste collection and processing performances in settings in which one input (waste costs) is shared among treatment efforts of multiple municipal solid waste fractions. The main advantage of this version of DEA is that it not only provides an estimate of the municipalities overall efficiency but also estimates of the municipalities' efficiency in the treatment of the different fractions of municipal solid waste (MSW). To illustrate the practical usefulness of the shared input DEAmodel, we apply the model to data on 293 municipalities in Flanders, Belgium, for the year 2008 .
\end{abstract}

Keywords: Municipal solid waste; Cost efficiency; Data Envelopment Analysis.

JEL-classification: H41; H50; Q53; Q58

Forthcoming in 'Waste Management': http://www.journals.elsevier.com/waste-management/

Corresponding author: Nicky.Rogge, tel.: +3226098834

E-mail address: Nicky.Rogge@hubrussel.be; Nicky.Rogge@econ.kuleuven.be 